\title{
Leidensverlängerung ist ein Behandlungsfehler!
}

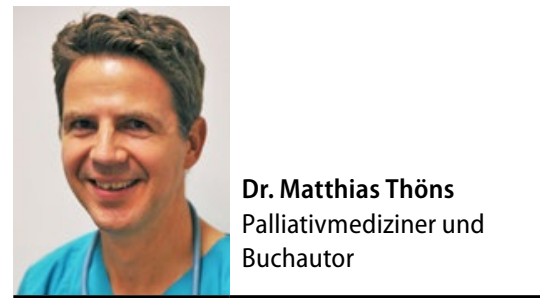

\begin{abstract}
Das Leben moribunder Patienten in Deutschland wird teils über Jahre intensivmedizinisch verlängert. Die behandelnden Ärzte fühlen sich dabei oft juristisch zur Sondenernährung gezwungen. Ein aktuelles Urteil schafft nun zumindest bei Demenzpatienten mehr Klarheit.
\end{abstract}

Die Ernährung via PEG-Magensonde bei Demenzbetroffenen wird kontrovers diskutiert. Die Deutsche Gesellschaft für Geriatrie stuft sie bei fortgeschrittener Demenz als „nicht indiziert“ ein. Die orale Ernährungshilfe ist bezüglich Sterblichkeit, Aspiration, funktionellem Status und Wohlbefinden mindestens so effektiv wie eine Sondenernährung, die Mortalität sogar geringer.

Anfang des Jahres kam nun ein juristischer Paukenschlag aus Bayern: Das Landgericht München I stufte die Sondenernährung ohne Therapieziel als ärztlichen Behandlungsfehler ein. Im konkreten Fall ging es um einen 82-jährigen Pflegeheimpatient mit weit fortgeschrittener Demenz, der von 2006 bis zu seinem Tod Ende 2011 künstlich ernährt wurde. Ein Berufsbetreuer hatte die Maßnahme ohne Rücksprache mit den Söhnen genehmigt.

\section{Erhebliche Qual am Lebensende}

In seinen letzten Jahren litt der Patient erheblich unter Rigor, spastischen Tetraparesen, schmerzhaften Kontrakturen und Druckgeschwüren. Er starb infolge einer Aspirationspneumonie als Komplikation der PEG. Der Sohn verklagte den Hausarzt wegen der Fortsetzung der Ernährung.

Das Gericht sah einen Behandlungsfehler darin, die Ernährung mittels PEG ohne Behandlungsziel fortgesetzt zu haben. Der Hausarzt sei ab Anfang 2010 verpflichtet gewesen, den Betreuer darüber in Kenntnis zu setzen, dass ein

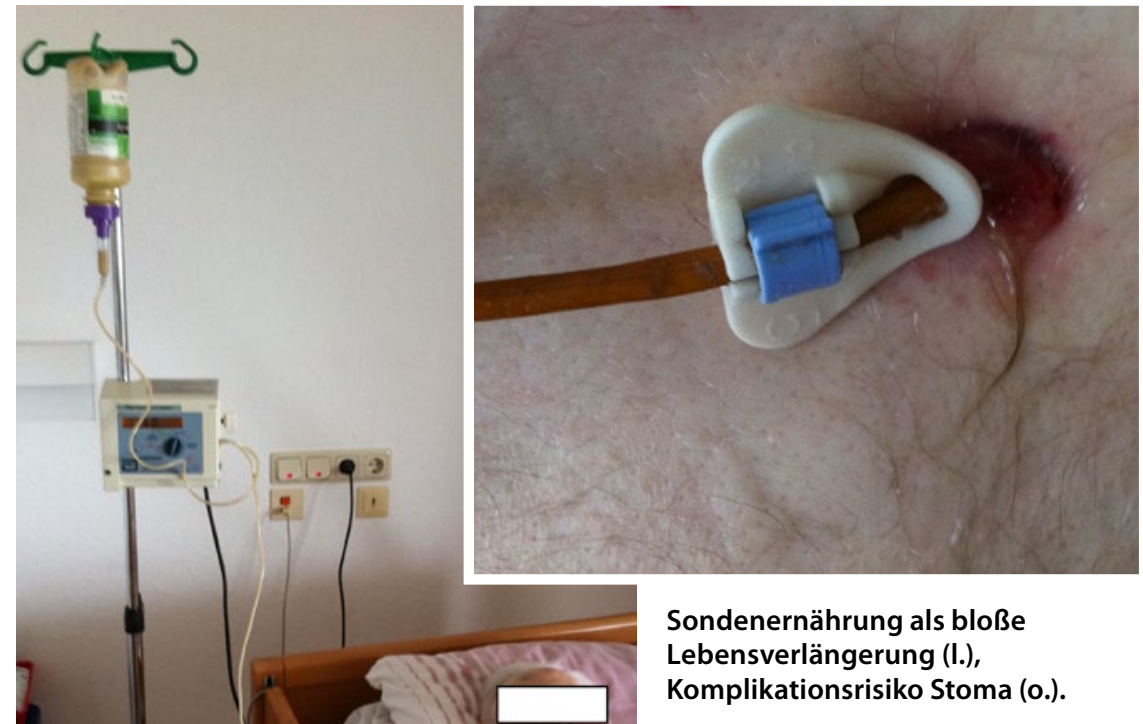

ist. Die Indikation muss fortlaufend überprüft werden - und Hausärzte sind gut beraten, sich an diese Vorgabe zu halten. Lässt sich kein therapeutischer Nutzen mehr erkennen, muss der rechtli-

über die reine Lebenserhaltung hinausgehendes Therapieziel nicht mehr zu erreichen war. Ein Schmerzensgeldanspruch wurde allerdings abgelehnt, da nicht bewiesen worden sei, dass ein klärendes Gespräch zur Beendigung der PEG-Ernährung geführt hätte. Dagegen wurde Berufung eingereicht.

Erstmals hat ein Landgericht entschieden, dass die künstliche Lebensverlängerung durch eine Magensonde ohne Therapieziel, also alleine lebens- und leidensverlängernd, ein Behandlungsfehler che Verteter des Patienten umgehend informiert werden.

Das Urteil lenkt indes weitere Aufmerksamkeit auf das wachsende Problem der Übertherapie am Lebensende. Inhaltlich ist es ein Meilenstein auf dem Weg zu einer humaneren Sterbebegleitung. Ob der mitunter zynische Leitsatz „in dubio pro vita“ universell gilt, ist nun zweifelhaft.

- Der Autor ist als Anästhesist und Palliativmediziner in Witten niedergelassen. 2016 erschien sein Buch „Patient ohne Verfügung" im Piper Verlag. 